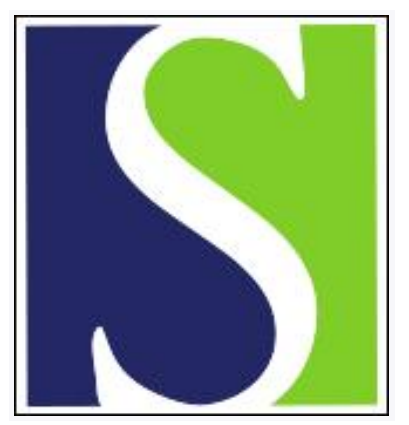

Scand J Work Environ Health 2004;30(6):477-485

https://doi.org/10.5271/sjweh.837

Issue date: Dec 2004

Job strain in relation to ambulatory blood pressure, heart rate, and heart rate variability among female nurses

by Riese H, Van Doornen LJP, Houtman ILD, De Geus EJC

Affiliation: Department of Psychiatry, University of Groningen, PO Box 30001, 9700 RB Groningen, The Netherlands. H.Riese@med.rug.nl

Refers to the following texts of the Journal: 1998;24(5):334-343 1998;24(1):54-61

The following articles refer to this text: 2006;32(6):482-492; SJWEH Supplements 2008;(6):41-51; 2014;40(2):109-132

Key terms: ambulatory blood pressure; decision latitude; heart rate; heart rate variability; job demand; job strain; real life; risk factor; social support; woman; work stress

This article in PubMed: www.ncbi.nlm.nih.gov/pubmed/15635758

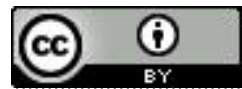




\title{
Job strain in relation to ambulatory blood pressure, heart rate, and heart rate variability among female nurses
}

\author{
by Harriëtte Riese, PhD, ${ }^{1}$ Lorenz JP Van Doornen, PhD, ${ }^{2}$ Irene LD Houtman, PhD, ${ }^{3}$ Eco JC De Geus, PhD ${ }^{1}$
}

\begin{abstract}
Riese H, Van Doornen LJP, Houtman ILD, De Geus EJC. Job strain in relation to ambulatory blood pressure, heart rate, and heart rate variability among female nurses. Scand J Work Environ Health 2004;30(6):477-485.

Objective This study examined the effects of exposure to job strain on independent predictors of cardiovascular disease (ambulatory blood pressure, heart rate, and heart rate variability).

Methods The participants comprised a homogeneous group of 159 healthy female nurses [mean age 35.9 (SD 8.5) years]. The choice of this population minimized variance attributable to gender, socioeconomic status, and work characteristics. Job demands, decision latitude, and social support were measured with the Karasek job content questionnaire, which was administered twice with an average interval of 12.2 months. The nurses' scores for job demands and decision latitude on both occasions were used to define their job-strain category. Ambulatory blood pressure, heart rate, and heart rate variability were assessed on a workday and a day of leisure. Results No effect on the ambulatory levels of blood pressure, heart rate, or heart rate variability was found for job strain by itself or in interaction with social support. In addition, job strain was not associated with differences in short-term or long-term physiological recovery during sleep after a workday or a day of leisure. High job demand was associated with higher systolic blood pressure at work and with higher diastolic blood pressure at work, but the latter association was found only when decision latitude was concurrently high, rather than low. Conclusions High job strain among young female nurses is not associated with an unfavorable ambulatory cardiovascular profile. The robust effect of job strain on male health appears to be less apparent for women.
\end{abstract}

Key terms risk factor, cardiovascular; decision latitude; job demand; real life; support, social; women; work stress.

High job strain is associated with an increased risk of cardiovascular disease (CVD) (1-3), and a lack of social support at work further increases this risk (4-6) for both men and women. The association is usually studied in populations of (predominantly) men. In this study we examined the effects of exposure to job strain (7) and social support on three potential mediators between these psychological stressors and three CVD variables (ambulatory blood pressure, heart rate, and heart rate variability) in a group of female nurses. These three cardiovascular variables are independent predictors of CVD (8-10), and their prolonged ambulatory recording in real-life settings increases their predictive power for disease end points (11). Several, but not all, job-strain or social support studies have shown an association with ambulatory blood pressure or heart rate among men, both cross-sectionally and prospectively (12-18). Findings for women, however, are more sparse and currently inconclusive (19, 20).

Various studies have shown that reduced heart rate variability is associated with a progression of focal coronary atherosclerosis (21) and cardiovascular morbidity and mortality $(9,22-24)$. With the use of the effortreward imbalance scale (25), ambulatory heart rate variability has been shown to be associated with the work stress of men (26). To our knowledge, the association between job strain and ambulatory heart rate variability has been studied only once in a mixed $(\mathrm{N}=113$ men, $\mathrm{N}=22$ women) population of shift workers (27). An elevated percentage of spectral power in the low-frequency band $(0.04-0.15 \mathrm{~Hz})$ in high-strain jobs was reported, but no difference was found in spectral power between the groups in the high-frequency band or a heart rate variability measure in the time domain.

1 Department of Biological Psychology, Vrije Universiteit, Amsterdam, The Netherlands.

2 Department of Health Psychology, University of Utrecht, Utrecht, The Netherlands,

3 TNO Work and Employment, Hoofddorp, The Netherlands.

Reprint requests to: Dr H Riese, Department of Psychiatry, University of Groningen, PO Box 30001, 9700 RB Groningen, The Netherlands. [E-mail: H.Riese@med.rug.nl] 
Our present study was carried out with a study population of healthy female nurses with a relatively homogeneous set of worktasks. This approach contrasts that of most previous studies, which have recruited participants from very different occupations $(28,29)$. Using a single occupational group, however, minimizes variance attributable to latent disease, gender, socioeconomic status, and work characteristics. In spite of the homogeneity of the work setting, a large variation in job strain has been shown to exist among Dutch nurses (30). Clearly, these differences in job strain indicate subjectively experienced job demands and decision latitude rather than objective job characteristics. Because all prevailing psychosomatic theories emphasize the importance of subjective appraisal as the main source of pathophysiological stress reactivity $(31,32)$, we expected subjective job strain to affect CVD risk significantly.

Blood pressure, heart rate, and the root-meansquared successive differences (RMSSD) between two $\mathrm{R}$-peak intervals, a reliable time-domain measure of heart rate variability (33), were assessed with ambulatory monitoring on both a workday and a day of leisure. Although ambulatory recording has better ecological validity, the lack of experimental control over participants' posture and physical activity can be a major source of confounding. Posture and physical activity are known to explain the largest part of the variance in ambulatory heart rate and blood pressure (34), and they may not be randomly distributed between nurses high and low in job strain. Previous studies reporting on the relation between psychosocial factors and ambulatory blood pressure mostly failed to take posture and physical activity into account $(28,29,35,36)$, and this failure may have compromised their assessment of jobstrain effects. In our study, therefore, we analyzed ambulatory data after careful stratification by posture and activity.

To make sure that we dealt with stable individual differences in job strain, we had the participants fill out the job-strain questionnaire twice over a period of a year, for a comparable prolonged cross-sectional design, as previously described by Schnall et al (16). On each occasion, we tested whether the participants were in the high job-strain quadrant (yes-no). This procedure led to four job-strain groups (no-no; yes-no; no-yes; yesyes) that were hypothesized to have increasingly unfavorable cardiovascular risk profiles. Across ambulatory measurements with comparable posture or activity, the yes-yes group would have higher heart rate and blood pressure, and lower RMSSD levels than women in the other groups. Low social support was expected to increase subjective strain even further and to interact with job strain to produce even more unfavorable ambulatory profiles. Since it has been suggested that low control over the work process or high job demands can increase disease risk in isolation $(2,37)$, we also tested for an association of job demands and decision latitude with ambulatory risk factors.

\section{Study population and methods}

\section{Study population}

The sample of nurses has been described extensively elsewhere $(38,39)$. Briefly, 1068 nurses received a job content questionnaire to characterize job strain at time 1. Of the 662 respondents (response rate $62 \%$ ), 107 were men, and 224 of the female nurses did not accept the invitation to participate in the current study. Therefore, 331 female nurses were eligible for participation (response rate $60 \%$ ). The female nonvolunteers did not differ from the volunteers with respect to job demands, skill discretion, decision authority, social support, physical load at work, age, marital status, number of hours employed per week, duration of employment in current position, or number of years involved in shiftwork (39). Of the 331 volunteers, 172 were excluded from the final sample because they were employed $<24$ hours a week $(\mathrm{N}=76)$, were not educated or employed as a registered nurse $(\mathrm{N}=32)$, were not working in morning shifts $(\mathrm{N}=9)$, could not be contacted $(\mathrm{N}=11)$, were pregnant, lactating or on maternity leave $(\mathrm{N}=13)$, changed jobs $(\mathrm{N}=17)$, were on sick leave, suffered from chronic disease or received medical treatment for cardiac disease, hypertension, hyperlipidemia or depression $(\mathrm{N}=7)$, or had experienced a major life event in the past 3 months (eg, divorce or disease or death of a parent, spouse or child) $(\mathrm{N}=7)$. A final total of 159 nurses with comparable job descriptions were included in the study. Their average age was 35.9 (SD 8.5) years, and their mean employment duration in their current position was 7.4 (SD 8.1) years. The Vrije Universiteit Medical Ethics Committee approved the study. Written informed consent was obtained from all the participants.

\section{Procedure}

At an average interval of 12.2 months after the first mailing, the participants were contacted again and scheduled for an ambulatory recording. Prior to their participation, all the nurses filled out questionnaires, including the job content questionnaire, for a second time (time 2) and attended a brief general (health) interview to provide information on personality, mood, educational level, demographics, years employed in the current position and shiftwork, use of oral contraceptives, phase in menstrual cycle, smoking behavior, and alcohol and coffee consumption. Waist and hip circumferences were measured for the calculation of the waist-to-hip 
ratio. The nurses wore the ambulatory monitoring devices for 24 hours on a workday and a day of leisure. The measurements were scheduled for a workweek that had three morning shifts (0730-1615) that had been preceded by at least 2 days of leisure. The workday measurement took place on the third morning shift. Before starting their normal work routines, the nurses came to a temporarily established research laboratory at their workplace. The ambulatory devices were fitted and their operation (attachment and detachment) was explained. Ambulatory measurements were continued until the next morning, when the nurses returned the monitors. For the measurement on the day of leisure, the nurses took the device home and attached the monitor themselves on the second of two successive days of leisure.

\section{Psychological assessment}

Job strain and social support. The nurses completed a shortened Dutch version of the job content questionnaire originating from the Dutch Monitor on Stress and Physical Load (40). The subscale for job demands was assessed with five dichotomous items. Skill discretion (five dichotomous items) and decision authority (seven dichotomous items) were combined in the subscale of decision latitude. The time between the first (time 1) and second (time 2) administration averaged 12.2 (range 8-15) months. Scores on the two subscales were acquired by simply computing sum scores (no=0, yes=1). Median values were computed for both subscales, and they were found to be identical for time 1 and time 2.

At each time point, a two-category variable was calculated for job strain. Nurses scoring above the median on the subscale for job demands (score $>3$ ) were assigned to the group with high job demands, whereas nurses scoring below the median on the subscale for decision latitude (scores $<10$ ) comprised the group with low decision latitude. Nurses scoring above the median for job demands and below the median for decision latitude were assigned to the group with high job strain (yes). All other nurses were assigned to the no-strain group (no). As depicted in figure 1, based on the nurses' job-strain status at time 1 and time 2, a four-category "composite job-strain variable" was calculated as previously described by Schnall et al (16). The scale reliability was acceptable for both job demands (Cronbach's alpha 0.75 for time 1 and 0.68 for time 2) and decision latitude (Cronbach's alpha 0.60 for time 1 and 0.64 for time 2). The 1 -year test-retest correlations were $0.44(\mathrm{P}<0.001)$ for job demands and $0.54(\mathrm{P}<0.001)$ for decision latitude. Social support was assessed at time 2 only by seven dichotomous items, referring to both coworker support and supervisory support according to Houtman et al (40). The scale reliability for social support was adequate (Cronbach alpha of 0.77 ). The means and standard deviations for job demands, decision latitude, and social support for the four groups (yes-yes, yes-no, etc) are given in table 1. Smoking, alcohol use, oral contraceptive use, phase in menstrual cycle, and physical characteristics like waist-to-hip ratio did not differ between the job-strain groups. In addition, the total employment duration and the number of years involved in shiftwork were comparable for all four groups.

Psychological well-being. Subjective physical load at work was assessed by 11 dichotomous items taken from the Dutch Monitor on Stress and Physical Load, which focuses on awkward postures and repetitive physical load (40). Depression was assessed with the CES-D (Center for Epidemiological Studies-Depression) questionnaire (41). Anxiety was assessed with the trait scale of the Spielberger State-Trait Anxiety Inventory (STAI) (42). Burnout was determined using the Utrecht Burnout Scale (UBOS) (43). Mood was assessed in the evening, close to bedtime, with a shortened version of the Profile of Mood States (POMS) (44). The POMS subscales for depression-dejection, fatigue-inertia, anger-hostility, and tension-anxiety items were summed to yield a negative mood index. The sum of the vigoractivity and friendliness subscales were used to form an index for positive mood.

\section{Ambulatory cardiovascular assessment}

Ambulatory cardiac measures were obtained with the VU-AMS device (version 4.6, TD-FPP, Vrije Universiteit, Amsterdam). The reliability and validity of the VU-AMS device have been described elsewhere (45). In brief, from the R-peak time-series an average value

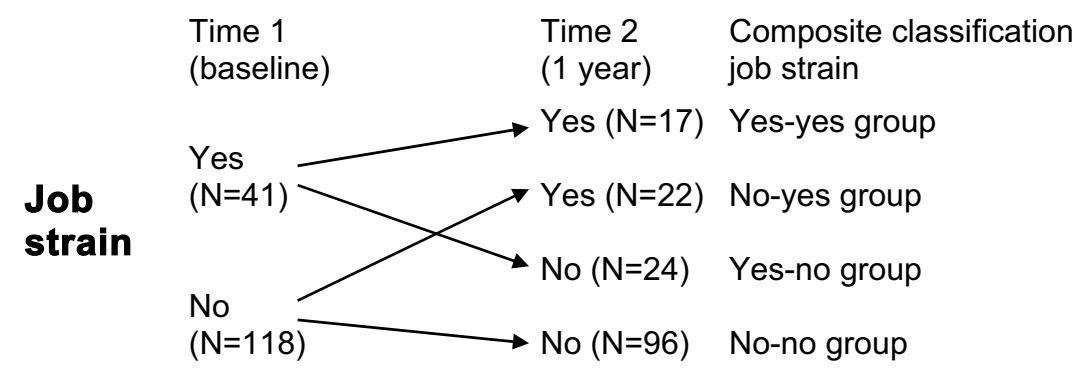

Figure 1. Cumulative exposure to job strain defined as a composite job-strain classification based on nurses' reported job-strain status at time 1 and time 2, according to Schnall et al (16). 
Table 1. Means and standard deviations for job demands, decision latitude, and social support for the four different job-strain groups separately.

\begin{tabular}{|c|c|c|c|c|c|c|c|c|c|c|}
\hline & \multicolumn{10}{|c|}{ Job strain } \\
\hline & \multicolumn{2}{|c|}{ No-no (N=96) } & \multicolumn{2}{|c|}{ Yes-no $(\mathrm{N}=24)$} & \multicolumn{2}{|c|}{ No-yes $(\mathrm{N}=22)$} & \multicolumn{2}{|c|}{ Yes-yes $(\mathrm{N}=17)$} & \multicolumn{2}{|c|}{ Total $(N=159)$} \\
\hline & Mean & SD & Mean & SD & Mean & $\mathrm{SD}$ & Mean & SD & Mean & SD \\
\hline \multicolumn{11}{|c|}{ Job demands } \\
\hline Time 1 & 2.2 & 1.4 & 4.5 & 0.5 & 2.5 & 1.2 & 4.6 & 0.5 & 2.8 & 1.6 \\
\hline Time 2 & 2.3 & 1.4 & 2.8 & 1.3 & 4.3 & 0.5 & 4.7 & 0.5 & 2.9 & 1.5 \\
\hline \multicolumn{11}{|c|}{ Decision latitude } \\
\hline Time 1 & 10.2 & 1.6 & 7.9 & 1.1 & 9.1 & 1.4 & 7.8 & 2.0 & 9.4 & 1.9 \\
\hline Time 2 & 9.8 & 1.9 & 9.3 & 1.6 & 7.8 & 1.2 & 7.2 & 1.9 & 9.2 & 2.0 \\
\hline \multicolumn{11}{|c|}{ Social support } \\
\hline Time 2 & 5.8 & 1.6 & 5.2 & 2.1 & 4.9 & 1.8 & 5.7 & 1.6 & 5.6 & 1.8 \\
\hline
\end{tabular}

for the interbeat interval (IBI) and the RMSSD between two peak intervals was obtained online from a 3-lead electrocardiograph for each 30 seconds. The graphs plotting the 30 -second averages of the IBI data against the RMSSD data were inspected visually for every participant. Irregularities were checked, and one participant was excluded from the final analyses as a result. In cardiology, RMSSD is one of the methods recommended for measuring heart rate variability (46), and it is very easy to obtain from ambulatory recordings of different time lengths.

Ambulatory systolic (SBP) and diastolic (DBP) blood pressure were recorded at regular intervals of 30 minutes by means of a Spacelabs 90207 device (SpaceLabs Medical, Redmond, USA). The ambulatory blood pressure device was removed before the participant went to sleep at night. The VU-AMS device was removed when the participant woke-up in the morning.

The VU-AMS device gave an auditory tone every $30( \pm 10)$ minutes during waking hours to prompt participants to fill out the diary. [See Riese et al (47) for an example of this procedure.] The nurses were instructed to write down the time, activities, bodily postures, and physical load in chronological order. The device also contained an accelerometer sensitive to changes in vertical acceleration. With the use of an interactive graphic program, this motility signal confirmed the information about type of (changes in) posture and activity from the diary. Stationary periods (same posture, same activity) were coded for posture, activity, day, and time of day. The mean values for heart rate and RMSSD for these coded fragments were calculated by the program and stored simultaneously with start and end time and the duration of the period. Each blood pressure value from the Spacelabs device was coded analog to the VU-AMS data. Criteria given in earlier recommendations were used for excluding erroneous blood pressure readings and outliers (48). Missing data were handled by imputing the value of the same person in the same activity category on the other registration day. Since nursing is a physically active job and posture and activities are substantially correlated (49), we aggregated the ambulatory data over coded activity periods before testing for possible group differences. Ambulatory measures for each of the 24-hour sessions were assigned to the following four physical-activity categories (50): (i) lying (during night time sleep), (ii) sitting activities (eg, desk work, watching television), (iii) light physical activities (eg, walking, light jobs at work or at home), and (iv) medium-heavy physical activities (eg, pushing a bed containing a patient, carrying heavy groceries).

On the average, the number of valid blood pressure readings during the workday and the day of leisure was 28.4 (SD 8.6, range 7-49) and 24.8 (SD 8.3, range 8$51)$, respectively. These numbers did not differ between the four job-strain categories on either the workday $[\mathrm{F}(3,150)=0.02, \quad \mathrm{P}=0.99]$ or the day of leisure $[F(3,150)=0.17, \mathrm{P}=0.92]$. Altogether $14.0 \%$ of the total readings for ambulatory heart rate and RMSSD had to be discarded due to ambiguous diary entries (13\%) or loose electrode contact $(1 \%)$. The amount of missing data did not differ between the job-strain groups for either the workday $[\mathrm{F}(3,153)=1.05, \mathrm{P}=0.37]$ or the day of leisure $[\mathrm{F}(3,153)=1.30, \mathrm{P}=0.28]$. The medium-heavy activity category, however, was badly filled, particularly on the day of leisure and, therefore, removed from further analyses.

\section{Statistical analysis}

Analyses of variance were performed with a general linear modeling (GLM) procedure in SPSS11.0 (SPSS Inc, Chicago, IL, USA) to test for differences in psychological well-being at time 2 as a function of the job-strain categories (no-no, yes-no, no-yes, yes-yes). Social support, as assessed at time 2, was entered as a covariate.

To test the association between ambulatory cardiovascular risk measures and job strain, bivariate GLM 
was performed for the ambulatory "cardiac" (IBI and RMSSD), and "blood pressure" (DBP and SBP) clusters separately. A repeated-measurement design was used with the job-strain categories (no-no, yes-no, noyes, yes-yes), measurement day (workday, day of leisure), and the category for posture-physical activity (sitting only, mild physical activity, and, for IBI and RMSSD, also night-time sleep). Social support at time 2 , age, oral contraceptive use, and waist-to-hip ratio were entered as covariates. A full model with all of the main and interaction terms was initially specified. Subsequently, nonsignificant interactions were removed in a step-down procedure that ended when all the remaining effects were part of a significant interaction or only the main effects were left (51).

To test the association between the ambulatory cardiovascular risk measure and job demands or decision latitude in isolation, multiple stepwise regression analyses were performed using the continuous scores of the questionnaires taken at time 2 only. Job demands and decision latitude assessed at time 2 , and their interaction term (job strain), social support, and job strain by social support were entered as possible predictors for IBI, RMSSD, SBP, and DBP levels in the three categories for posture-physical activity on each of the two ambulatory measurement days.

\section{Results}

\section{Job strain}

Psychological well-being. Systematic group differences emerged with regard to the questionnaires pertaining to psychological well-being as assessed at time 2 . The nurses reporting high job strain at time 2 were, compared with the "no-strain" nurses, more depressed $[F(3,155)=3.6, \quad P=0.02]$, anxious $[F(3,155)=2.9$, $\mathrm{P}=0.04]$, burned-out according to all three subscales $[F(3,155)=4.1, P=0.008$ for emotional exhaustion, $\mathrm{F}(1,155)=5.9, \mathrm{P}=0.001$ for depersonalization, and $\mathrm{F}(1,155)=3.0, \mathrm{P}=0.03$ for personal accomplishment] and reported, on the average, more negative mood on both monitoring days $[\mathrm{F}(3,155)=3.6, \mathrm{P}=0.02]$.

The nurses in the yes-yes group experienced a significantly higher subjective physical load at work $[F(3,155)=6.7, P<0.001]$. This result was not paralleled by the finding of the objective physical-activity measure as obtained from the combined diary and vertical accelerometer data. A comparison of the time spent in different activities between the four job-strain categories on the workday showed that the groups did not differ in time spent lying (during sleep) $[\mathrm{F}(3,134)=0.61$, $\mathrm{P}=0.61]$, sitting $[(\mathrm{F}(3,153)=0.52, \mathrm{P}=0.67]$, or doing light physical activities $[\mathrm{F}(3,153)=1.38, \mathrm{P}=0.25]$.
Ambulatory measurements. Figure 2 shows the cardiovascular profile for the four job-strain groups across three physical-activity categories on the workday and day of leisure. The decrease in IBI and RMSSD with increasing physical activity (from sleeping to sitting to light physical activity) was stronger for the workday than for the day of leisure [multivariate $\mathrm{F}(4,146)=7.9$, $\mathrm{P}<0.001$; univariate IBI and RMSSD $\mathrm{P}<0.001$ and $\mathrm{P}=0.031$, respectively]. As expected blood pressure was higher on the workday than on the day of leisure [multivariate $\mathrm{F}(2,147)=24.1, \mathrm{P}<0.001$; univariate $\mathrm{SBP}$ and DBP $\mathrm{P}<0.001$ and $\mathrm{P}<0.001$, respectively] and higher during physical activity than during sitting [multivariate $\mathrm{F}(2,147)=65.6, \mathrm{P}<0.001$; univariate SBP and DBP $\mathrm{P}<0.001$ and $\mathrm{P}<0.001$, respectively] . Job strain by itself did not yield any effects on IBI, RMSSD, SBP, or DBP. In addition, no differences were observed in shortterm or long-term recovery during sleep after a workday or day of leisure.

\section{Job demands and decision latitude}

In the multiple regression (stepwise) analyses on the continuous scores current job demands, decision latitude, and their interaction terms did not explain the IBI, RMSSD, SBP or DBP levels in a systematic way for a workday or day of leisure. Social support at time 2 also failed to produce the expected effects. The interaction between decision latitude and job demands did affect the DBP level during sitting during the workday ( $\beta=0.19, P=0.02)$, but the highest DBP values were found for nurses reporting a combination of high job demands and high decision latitude, and this finding countered the theoretical expectation. Only a single effect was in the expected direction, that of high job demands predicting higher SBP during sitting during the workday ( $\beta=0.17, \mathrm{P}=0.04)$.

In summary, effects of job strain were found with respect to the psychological variables, but there was no effect of job strain, either by itself or in interaction with social support, on the ambulatory levels of IBI, RMSSD, SBP, or DBP. Job demands and decision latitude at the time of the ambulatory monitoring also failed to show the expected associations with an unfavorable ambulatory cardiovascular risk profile.

\section{Discussion}

Job strain, assessed as low decision latitude in combination with high job demands of at least 1-year duration, was found to be associated with the impaired psychological well-being of female nurses. This result corresponds well with findings from comparable studies on 

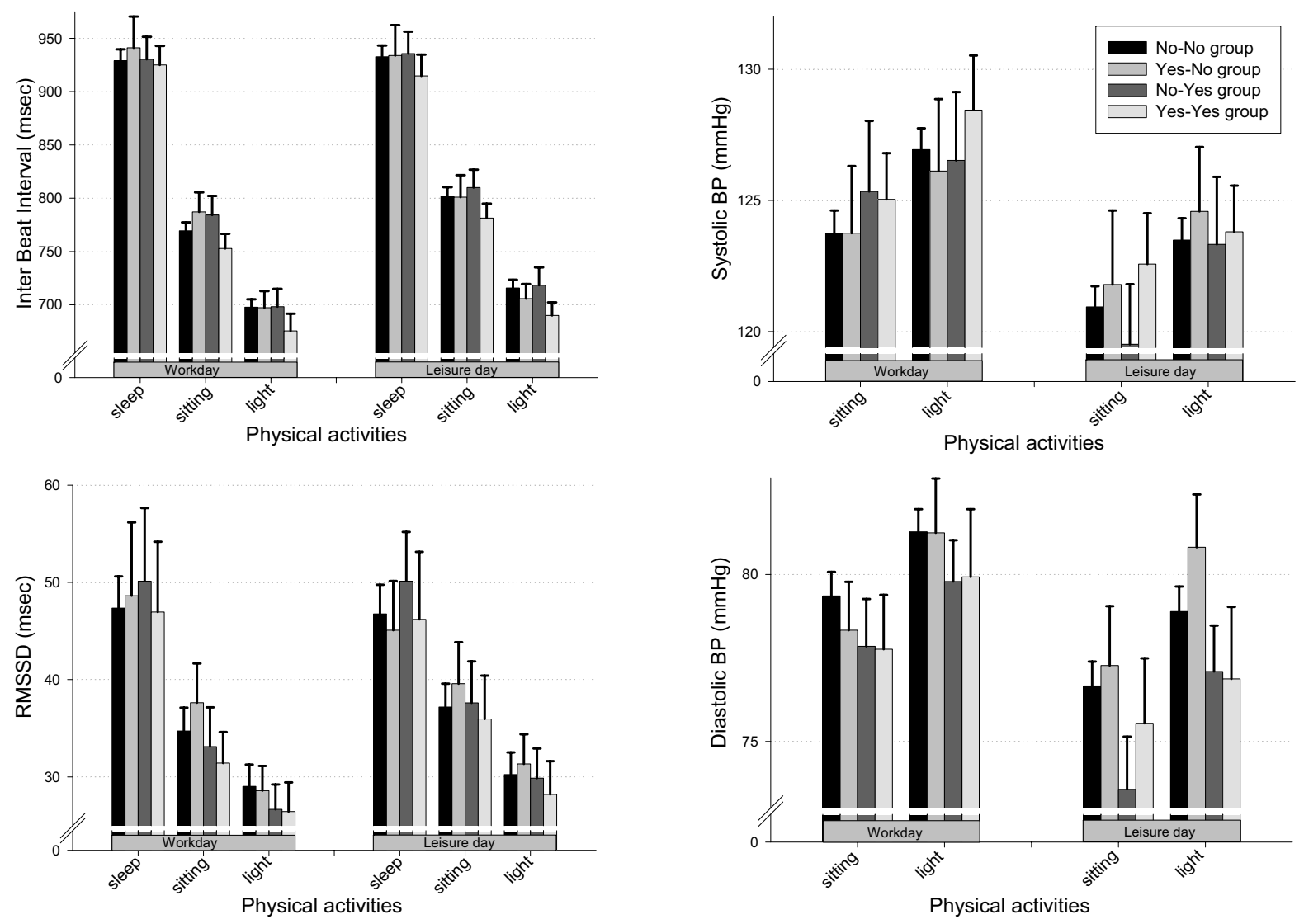

Figure 2. Mean interbeat intervals, root-mean-squared successive differences (RMSSD), and systolic and diastolic blood pressure (BP) during sitting, light physical activities, and sleep on the workday and the day of leisure, according to the different job-strain categories, given separately. (vertical bars $=$ standard errors of the mean)

female workers $(52,53)$. In spite of the association with low psychological well-being, no evidence was found for detrimental effects of job strain on ambulatory risk factors for CVD, either by itself or in interaction with social support. An important asset of this study was that the results were not confounded by "trivial" differences in physical activity during the monitoring. We made sure to compare participants only within categories of activity of similar posture and comparable physical load and did not find group differences in the time spent in various activities.

The null findings for job strain in relation to heart rate and blood pressure are at odds with the significant effects of job strain, or other formulations of high work stress, on blood pressure and heart rate, as repeatedly found in male or mixed gender samples. [See, for example, Schnall et al $(15,16)$ and Van Egeren (54).] Furthermore, adverse effects of chronic job strain or low support at work on ambulatory blood pressure $(28,35$, $55,56)$ or heart rate $(18)$ have also been found in all the female samples. For instance, in a homogenous group of female nurses $(\mathrm{N}=56)$, Theorell et al (56) found that job strain was associated with elevated ambulatory blood-pressure levels during workhours on a normal workday. However, this effect was not shown in a larger sample of nurses $(\mathrm{N}=138)$, who were measured four times for 24 hours (57), and some other studies on women have also failed to detect effects of job strain on ambulatory blood pressure $(12,19,57,58)$ or heart rate $(57)$.

A comparison of the studies with positive versus null findings suggests that most of the significant job-strain effects on blood pressure were obtained among women in heterogeneous or mainly white-collar occupations. In a homogeneous worksetting, differences in job strain are due to subjectively experienced job demands and decision latitude, rather than to objective job characteristics. This situation was illustrated in our study by the fact that the high subjective physical workload of the nurses with high job strain was not confirmed by the actual time spent in the physical activity, as obtained from the diary and vertical accelerometer data. Thus the low psychological well-being found with higher job strain may also influence the subjective recall of the intensity, duration, or frequency of physically demanding activities. Under the prevailing psychosomatic theories that emphasize subjective appraisal as the main source of stressinduced disease $(31,32)$, we expected subjective job strain to affect the ambulatory risk profile of the nurses 
significantly. However, it is possible that objective job characteristics are more important or that larger variance in subjective strain can be found in more heterogeneous worksettings.

Clearly, the detection of a significant job-strain effect depends on the mean and variance of job strain. Low job-strain levels and insufficient variation in job strain would attenuate the associations with cardiovascular risk. Such an attenuation does not seem to be likely in this specific population. Previous studies in the Dutch health-care system have indicated that nurses are at risk of high workpace (59) and nurses are widely perceived to have emotionally and physically highly demanding jobs (60). The average score and standard deviation of job demands, decision latitude, or social support for the nurses studied were similar to those found in a Dutch reference population of 10512 men and women working in various jobs of the Dutch health-care system, mostly nurses (30). It is difficult to conceive of this huge reference population as being restricted in range or having lower-than-average job strain.

Another explanation for the absence of detrimental effects of job strain in our study is the younger age of our nurses (age range of 25-50 years) compared with that of women in the study reporting detrimental effects of job strain (range 25-64 years) (35). Our nurses may not have been exposed to chronic job strain for a long period, since we ensured the stability of high job strain for a 1-year period only. In addition, since our nurses were largely premenopausal, they may still have experienced the putative protective effects of estrogen (61). Job-strain effects on women may become apparent only after menopause. Since only 1 out of the 17 postmenopausal nurses reported high job strain, this question could not be resolved in our study. However, in the study of Laflamme et al (35), in which a positive association between job strain and SBP was found, the number of women in the oldest age group (55-64 years) was only seven, and, therefore, could not have accounted for the positive finding, and, therefore, this explanation is less plausible.

In the Nurses Health Study, job strain, job demands, and decision latitude were not associated with coronary heart disease (CHD) after a 4-year follow-up period (62). Although this was an impressive prospective cohort study, due to the relatively short follow-up period, cumulative effects of adverse job characteristics on a slowly progressing clinical end point like CHD may have been missed. In an 11-year follow-up, job strain did predict CHD events among female white-collar workers, but intriguingly high job demands in particular predicted the incidence of fatal CHD and nonfatal myocardial infarction (2). The results of our study suggest that elevated SBP in association with high job demands is a potential mediator in the latter relation.
We found that nurses reporting higher, rather than lower, current decision latitude had a higher DBP. Although counterintuitive, this finding is in line with results reported by Light et al (12), in that women scoring high on skill discretion (an index of decision latitude) had elevated DBP at work. Another interesting finding is that our nurses with both high job demands and high decision latitude had the highest DBP at work. This finding is remarkable since, in the original description of the model, these so-called 'active jobs' are assumed to develop "feelings of mastery that inhibit strain perception" and in this way should be associated with lower risk (7). However, our findings are in line with the results of a study on job strain and preclinical carotid atherosclerosis. In a heterogeneous occupational population, higher carotid plaque prevalence and thicker carotid artery intima-media thickness were found among women in high-strain jobs and in active jobs. Although adjustment for occupational status reduced the magnitude of the association among the women with high strain, it did not affect the association found for women in active jobs (63).

The results of our study suggest that, for women, the detrimental effects of work stress are not as straightforward as hypothesized in the Karasek job-strain model (7). Moreover, it suggests that specific toxic psychosocial characteristics can be expected for either gender and for each occupational setting. We recommend that future studies set up to identify toxic characteristics use relatively homogeneous populations to control for false positive findings with respect to job strain in relation to occupational status, socioeconomic status, or work characteristics.

Overall, our results are well in agreement with the general finding that the original concept of job strain applies more to men than to women (64), with the possible exception of highly educated women (27). It remains unclear whether these gender differences in the detrimental effects of job strain are due to psychological or physiological influences not assessed in the current study (eg, the effects of menopausal status, sensitivity to the effect of catecholamines and cortisol on the target organs, social gender roles, socialized gender roles, or attitudes in social situations) $(65,66)$.

\section{Acknowledgments}

This work was supported by a grant from the Dutch Heart Foundation (NHS grant 94.030). Paul FC Groot, MSc, Technical Department, Vrije Universiteit, Amsterdam, is acknowledged for his technical support with the VU-AMS. 


\section{References}

1. Kivimäki M, Leino-Arjas $\mathrm{P}$, Luukkonen R, Riihimäki H, Vahtera J, Kirjonen J. Work stress and risk of cardiovascular mortality: prospective cohort study of industrial employees. BMJ 2002;325(7369):857.

2. Kuper H, Marmot M. Job strain, job demands, decision latitude, and risk of coronary heart disease within the Whitehall II study. J Epidemiol Community Health 2003;57(2):147-53.

3. Schnall PL, Landsbergis PA, Baker D. Job strain and cardiovascular disease. Annu Rev Public Health 1994;15:381-411.

4. Johnson JV, Stewart W, Hall EM, Fredlund P, Theorell T. Long-term psychosocial work environment and cardiovascular mortality among Swedish men. Am J Public Health 1996;86(3):324-31.

5. Johnson JV, Hall EM, Theorell T. Combined effects of job strain and social isolation on cardiovascular disease morbidity and mortality in a random sample of the Swedish male working population. Scand J Work Environ Health 1989; 15(4):271-9.

6. Orth-Gomér K, Horsten M, Wamala S, Mittleman M, Kirkeeide R, Svane B, et al. Social relations and extent and severity of coronary artery disease: the Stockholm female coronary risk study. Eur Heart J 1998;19(11):1648-56.

7. Karasek RA, Theorell T. Healthy work: stress productivity, and the reconstruction of working life. New York (NY): Basic Books; 1990.

8. Staessen JA, Asmar R, De Buyzere M, Imai Y, Parati G, Shimada K, et al. Task force II: blood pressure measurement and cardiovascular outcome. Blood Press Monit 2001;6:35570 .

9. Stein PK, Kleiger RE. Insights from the study of heart variability. Annu Rev Med 1999;50:249-61.

10. Kannel WB, Kannel C, Paffenbarger RSJ, Cupples LA. Heart rate and cardiovascular mortality: the Framingham Study. Am Heart J 1987;113(6):1489-94.

11. Verdecchia P, Porcellati C, Schillaci G, Borgioni C, Ciucci A, Battistelli M, et al. Ambulatory blood pressure: an independent predictor of prognosis in essential hypertension. Hypertension 1994;24:793-801.

12. Light KC, Turner R, Hinderliter AL. Job strain and ambulatory work blood pressure in healthy young men and woman. Hypertension 1992;20:214-8.

13. Pieper C, LaCroix AZ, Karasek RA. The relation of psychosocial dimensions of work with coronary heart disease risk factors: a meta-analysis of five United States data bases. Am J Epidemiol 1989;129(3):483-94.

14. Schnall PL, Pieper C, Schwartz JE, Karasek RA, Schlussel Y, Devereux RB, et al. The relationship between 'job strain,' workplace diastolic blood pressure, and left ventricular mass index: results of a case-control study. JAMA 1990;263:1929_ 35 .

15. Schnall PL, Schwartz JE, Landsbergis PA, Warren K, Pickering TG. Relation between job strain, alcohol, and ambulatory blood pressure. Hypertension 1992;19:488-94.

16. Schnall PL, Schwartz JE, Landsbergis PA, Warren K, Pickering TG. A longitudinal study of job strain and ambulatory blood pressure: results from a three-year follow-up. Psychosom Med 1998;60:697-706.

17. Uchino BN, Cacioppo JT, Kiecolt-Glaser JK. The relationship between social support and physiological processes: a review with emphasis on underlying mechanisms and implications for health. Psychol Bull 1996;119(3):488-531.

18. Undén AL, Orth-Gomér K, Elofsson S. Cardiovascular effects of social support in the work place: twenty-four-hour ECG monitoring of men and woman. Psychosom Med 1991; 53(1):50-60.

19. Pickering T. The effects of occupational stress on blood pressure in men and women. Acta Physiol Scand Suppl 1997; 640:125-8.

20. Cesana G, Sega R, Ferrario M, Chiodini P, Corrao G, Mancia G. Job strain and blood pressure in employed men and women: a pooled analysis of four northern Italian population samples. Psychosom Med 2003;65(4):558-63.

21. Huikuri HV, Jokinen V, Syvnne M, Nieminen MS, Airaksinen KEJ, Ikäheimo MJ, et al. Heart rate variability and progression of coronary atherosclerosis. Arterioscler Thromb Vasc Biol 1999;199:1979-85.

22. Bigger JT, Fleiss JL, Rolnitzky LM, Steinman RC. The ability of several short-term measures of RR variability to predict mortality after myocardial infarction. Circulation 1993; 88(3):927-34.

23. Singh JP, Larson MG, Tsuij H, Evans JC, O’Donnell CJ, Levy D. Reduced heart rate variability and new-onset hypertension: insights into pathogenesis of hypertension: the Framingham Heart Study. Hypertension 1998;32:293-7.

24. Tsuji H, Larson MG, Venditti FJ Jr, Manders ES, Evans JC, Feldman CL, et al. Impact of reduced heart rate variability on risk for cardiac events: the Framingham heart study. Circulation 1996;94(11):2850-5.

25. Siegrist J, Peter R. Job stressors and coping characteristics in work-related disease: issues of validity. Work Stress 1994; $8(2): 130-40$.

26. Vrijkotte TGM, Van Doornen LJP, De Geus EJC. Effects of workstress on ambulatory blood pressure, heart rate, and heart rate variability. Hypertension 2000;35(4):880-6.

27. Van Amelsvoort LGPM, Schouten EG, Maan AC, Swenne CA, Kok FJ. Occupational determinant of heart rate variability. Int Arch Occup Environ Health 2000;73(4):255-62.

28. Brisson C, Laflamme N, Moisan J, Milot A, Masse A, Vézine M. Effect of family responsibilities and job strain on ambulatory blood pressure among white-collar women. Psychosom Med 1999;61:205-13.

29. Horsten M, Ericson M, Perski A, Wamala SP, Schenck-Gustafsson K, Orth-Gomer K. Psychosocial factors and heart rate variability in healthy women. Psychosom Med 1999;61:49_ 57.

30. Houtman ILD, Zuidhof AJ, Van den Heuvel SG. Arbobeleid in ontwikkeling: werkdruk en RSI de belangrijkste problemen [Assessing occupational risk factors: job strain and RSI are the most important problems]. Leiden (The Netherlands): PGTNO; 1998.

31. Lovallo WR, Thomas TL. Stress hormones in psychophysiological research: emotional, behavioral, and cognitive implication. In: Cacioppo JT, Tassinary LG, Berntson G, editors. Handbook of Psychophysiology. New York (NY): Cambridge University Press; 2000. p 342-67.

32. Ursin H, Olff M. The stress response. In: Stanford SC, Salmon P, Gray JA, editors. Stress, from synapse to syndrome. London: London Academic Press; 1993. p 2-28.

33. Penttilä J, Helminen A, Jartti T, Kuusela T, Huikuri HV, Tulppo MP, et al. Time domain, geometrical and frequency domain analysis of cardiac vagal outflow: effects of various respiratory patterns. Clin Physiol 2001;21(3):365-76.

34. Kario K, Schwartz JE, Pickering TG. Ambulatory physical activity as a determinant of diurnal blood pressure variation. Hypertension 1999;34(4 Pt 1):685-91.

35. Laflamme N, Brisson C, Moisan J, Milot A, Mâsse B, Vézina 
M. Job strain and ambulatory blood pressure among female white-collar workers. Scand J work Environ Health 1998; 24(5):334-43.

36. Steptoe A, Cropley M, Joekes K. Job strain, blood pressure and response to uncontrollable stress. J Hypertens 1999; 17:193-200.

37. Bosma H, Marmot MG, Hemingway H, Nicholson AC, Brunner E, Stansfeld SA. Low job control and risk of coronary heart disease in Whitehall II (prospective cohort) study. BMJ 1997;314:558-65.

38. Riese H, Van Doornen LJP, Houtman ILD, De Geus EJC. Job strain and risk indicators for cardiovascular disease in young female nurses. Health Psychol 2000;19(5):429-40.

39. Riese H. Job strain and risk for cardiovascular disease in female nurses [dissertation]. Amsterdam: Vrije Universiteit; 2000.

40. Houtman ILD, Goudswaard A, Dhondt S, Vander Grinten MP, Hildebrandt VH, Van der Poel EGT. Dutch monitor on stress and physical load: risk factors, consequences, and preventive action. Occup Environ Med 1998;55:73-83.

41. Kohout FJ, Berkman LF, Evans DA, Cornoni-Huntley J. Two shorter forms of the CES-D depression symptoms index. J Aging Health 1993;5(2):179-93.

42. Van Der Ploeg HM, Defares PB, Spielberger CD. Handleiding bij de Zelf-Beoordelings Vragenlijst ZBV [The Dutch version of the Spielberger State-Trait Anxiety Inventory STAI-DY]. Lisse (The Netherlands): Swets \& Zeitlinger; 1981.

43. Schaufeli WB, Van Dierendonk D. The construct validity of two burnout measures. J Organ Behav 1993;14:631-47.

44. Wald FDM, Mellenbergh GJ. De verkorte versie van de Nederlandse vertaling van de Profile Of Mood States (POMS) [The short Dutch version of the Profile of Mood States (POMS)]. Ned Tijdschr Psychol 1990;45:86-90.

45. De Geus EJC, Van Doornen LJP. Ambulatory assessment of parasympathetic/sympathetic balance by impedance cardiography. In: Fahrenberg J, Myrtek M, editors. Ambulatory assessment: computer-assisted psychological and psychophysiological methods in monitoring and field studies. Göttingen (Germany): Hogrefe \& Huber Publishers; 1996. p 141-63.

46. Task force of the European Society of Cardiology and the North American Society of Pacing and Electrophysiology. Heart rate variability: standards of measurement, physiological interpretation and clinical use. Circulation 1996; 93(5):1043-65.

47. Riese H, Groot PFC, van den Berg M, Kupper NH, Magnee EHB, Rohaan EJ, et al. Large-scale ensemble averaging of ambulatory impedance cardiograms. Behav Res Methods Instrum Comput 2003;35(3):467-77.

48. Berardi L, Chau NP, Chanudet X, Vilar J, Larroque P. Ambulatory blood pressure monitoring: a critical review of the current methods to handle outliers. J Hypertens 1992;10:12438.

49. Van Egeren LF, Gellman M. Cardiovascular reactivity to everyday events. In: Johnson EH, Gentry WD, Julius S, editors. Personality, elevated blood pressure, and essential hypertension. Washington (DC): Hemisphere; 1992. p 135-50.

50. Ainsworth BE, Haskell WL, Leon AS, Jacobs DR Jr, Montoye HJ, Sallis JF, et al. Compendium of physical activities: classification of energy costs of human physical activities. Med Sci Sports Exerc 1993;25:71-80.
51. McCullagh P, Nelder JA. Generalized linear models. 2nd ed. London: Chapman and Hall; 1989.

52. Bourbonnais R, Corneau M, Vezina M, Dion G. Job strain, psychological distress, and burnout in nurses. Am J Ind Med 1998;34:20-8.

53. Williams RB, Blumenthal JA, Helms MJ, Luecken L, Pieper $\mathrm{CF}$, Siegler IC, et al. Psychosocial correlates of job strain in a sample of working woman. Arch Gen Psychiatry 1997; 54:543-8.

54. Van Egeren LF. The relationship between job strain and blood pressure at work, at home, and during sleep. Psychosom Med 1992;54:337-43.

55. Blumenthal JA, Thyrum ET, Siegel WC. Contribution of job strain, job status and marital status to laboratory and ambulatory blood pressure in patients with mild hypertension. J Psychosom Res 1995;39:133-44.

56. Theorell T, Ahlberg-Hulten G, Jodko M, Sigala F, de la Torre B. Influence of job strain and emotion on blood pressure in female hospital personnel during workhours. Scand J Work Environ Health 1993;19:313-8.

57. Goldstein IB, Shapiro D, Chicz-DeMet A, Guthrie D. Ambulatory blood pressure, heart rate, and neuroendocrine responses in women nurses during work and off work days. Psychosom Med 1999;61(3):387-96.

58. Matthews KA, Räikkönen K, Everson SA, Flory JD, Marco CA, Owens JF, et al. Do the daily experiences of healthy men and women vary according to occupational prestige and work strain? Psychosom Med 2000;62:346-53.

59. Houtman ILD, Kompier MAJ. Risk factors and occupational risk groups for work stress in The Netherlands. In: Sauter SL, Murphy LR, editors. Organizational risk factors for job stress. Washington (DC): American Psychological Association; 1995. p 209-25.

60. Amick III BC, Kawachi I, Coakley EH, Lerner D, Levine S, Colditz GA. Relationship of job strain and iso-strain to health status in a cohort of women in the Unites States. Scand J Work Environ Health 1998;24(1):54-61.

61. Palmer JR, Rosenberg L, Shapiro S. Reproductive factors and risk of myocardial infarction. Am J Epidemiol 1992;136:40816.

62. Lee S, Colditz G, Berkman L, Kawachi I. A prospective study of job strain and coronary heart disease in US women. Int $\mathrm{J}$ Epidemiol 2002;31(6):1147-53.

63. Rosvall M, Ostergren PO, Hedblad B, Isacsson SO, Janzon L, Berglund G. Work-related psychosocial factors and carotid atherosclerosis. Int J Epidemiol 2002;31(6):1169-78.

64. Pickering TG, Devereux RB, James GD, Gerin W, Landsbergis PA, Schnall PL, et al. Environmental influences on blood pressure and the role of job strain. J Hypertens Suppl 1996;14 Suppl 5:179-85.

65. Kop WJ. Acute and chronic psychological risk factors for coronary syndromes: moderating effects of coronary artery disease severity. J Psychosom Res 1997;43:167-81.

66. Theorell T. On cardiovascular health in woman: results from epidemiological and psychosocial studies in Sweden. In: Frankenhaeuser M, Lundberg U, Chesney M, editors. Woman, work and health. New York (NY): Plenum Press; 1991. p 187-204.

Received for publication: 5 December 2003 